\title{
The diagnostic accuracy of imaging modalities to detect pseudarthrosis after spinal fusion-a systematic review and meta-analysis of the literature
}

\author{
Marloes J. M. Peters ${ }^{1}$ (D) $\cdot$ Carolien H. G. Bastiaenen ${ }^{2} \cdot$ Boudewijn T. Brans $^{3} \cdot$ René E. Weijers $^{4} \cdot$ Paul C. Willems $^{1}$
}

Received: 1 November 2018 / Revised: 21 January 2019 / Accepted: 6 February 2019 / Published online: 23 February 2019

(C) The Author(s) 2019

\begin{abstract}
Objective The aim of the study was to determine the diagnostic accuracy of imaging modalities to detect pseudarthrosis after thoracolumbar spinal fusion, with surgical exploration as reference standard.

Materials and methods A systematic literature search for original studies was performed on the diagnostic accuracy of imaging as index test compared to surgical exploration as reference standard to diagnose pseudarthrosis after thoracolumbar spinal fusion. Diagnostic accuracy values were extracted and methodologic quality of studies was evaluated by the Quality Assessment of Diagnostic Accuracy Studies 2 (QUADAS-2) tool. Per modality, clinically comparable studies were included in subgroup metaanalysis and weighted odds ratios (ORs) were calculated using the random effects model.

Results Fifteen studies were included. Risk of bias was classified as high/unclear in 58\% of the studies. Concerns of applicability was classified as high/unclear in $40 \%$ of the studies. Four scintigraphy studies including 93 patients in total were pooled to OR = 2.91 (95\% confidence interval [CI]: 0.93-9.13). Five studies on plain radiography with 398 patients in total were pooled into $\mathrm{OR}=$ 7.07 (95\% CI: 2.97-16.86). Two studies evaluating flexion-extension radiography of 75 patients in total were pooled into $\mathrm{OR}=$ 4.00 (95\% CI: 0.15-105.96). Two studies of 68 patients in total were pooled for CT and yielded OR = 17.02 (95\% CI: 6.42-45.10). A single study reporting on polytomography, $\mathrm{OR}=10.15$ (95\% CI 5.49-18.78), was also considered to be an accurate study.

Conclusions With a pooled OR of 17.02, CT can be considered the most accurate imaging modality for the detection of pseudarthrosis after thoracolumbar spinal fusion from this review.
\end{abstract}

Keywords Meta-analysis $\cdot$ Spinal fusion $\cdot$ Diagnostics accuracy $\cdot$ Pseudarthrosis $\cdot$ Imaging

\section{Introduction}

Low back pain is a global health and socio-economic problem [1], as it is the leading cause of disability and work absenteeism in the Western world [2]. When conservative measures

Marloes J. M. Peters

marloes.peters@maastrichtuniversity.nl

1 Department of Orthopaedic Surgery, Maastricht University Medical Center, Maastricht, The Netherlands

2 Department of Epidemiology, Maastricht University, Maastricht, The Netherlands

3 Department of Nuclear Medicine, University Hospital Ghent, Ghent, Belgium

4 Department of Nuclear Medicine and Radiology, Maastricht University Medical Center, Maastricht, The Netherlands fail, operative intervention can be considered. Spinal fusion is a surgical procedure in which rigid fixation of vertebral segments is achieved by means of osteosynthesis and bone grafting to create definite bony fusion of the vertebrae involved. Failed spinal fusion may occur in $30-40 \%$ of spinal fusion patients [3, 4]. Pseudarthrosis is defined as the absence of solid bony fusion at a minimum follow-up of 6 months after surgery $[5,6]$. Pseudarthrosis can be associated with persistent or recurrent back and/or leg pain [7], but can also be asymptomatic [7-9]. Whether symptomatic or asymptomatic, pseudarthrosis increases the risk of material failure, late deformity, and neurological symptoms $[10,11]$.

Revision surgery is the preferred treatment in spinal fusion patients suffering from symptoms due to pseudarthrosis. Revision surgery is invasive, expensive, and may have a worse outcome than primary surgery $[12,13]$ and should only be performed when the pseudarthrosis diagnosis is irrefutable. Since symptoms 
of pseudarthrosis may be nonspecific and multiple individual sources of pain may contribute to the complex of symptoms [14], diagnostic tools are required to set the diagnosis. The gold standard for the diagnosis of pseudarthrosis is surgical exploration $[5,7,15,16]$, an invasive, costly, and nowadays rarely used test which is not desirable or ethical in patients without symptoms. The aim of the study was to determine the diagnostic accuracy of imaging modalities to detect pseudarthrosis after thoracolumbar spinal fusion, with surgical exploration as the reference standard.

\section{Materials and methods}

\section{Identification of studies}

This review was performed according to the PRISMA statement guidelines [17, 18]. A systematic literature search was conducted in the PubMed, EMBASE, and CINAHL databases from inception until February 2017 to identify relevant studies. A list of keywords and text words was formulated to describe the detection of pseudarthrosis by imaging as index test compared to surgical exploration as reference standard in patients after spinal fusion surgery. Terms for imaging: tomography, radiography, plain radiographs, MRI, CT, scintigraphy, SPECT, SPECT/CT, PET, PET/CT, DEXA. Terms for study design: diagnostic accuracy, precision, predictive value, sensitivity, specificity, false positive, false negative. Terms for patient population: spine, vertebrae, vertebral column, spinal fusion, spinal arthrodesis, spondylodesis, bone graft, pseudarthrosis, non-union, delayed union, clinical failure, surgical exploration, re-operation, second-look operation. The search was limited to the English language.

Once the search was completed, the resulting articles were checked for duplicates. Subsequently, two independent reviewers (PW, orthopedic surgeon with over 10 years of experience in spinal surgery and MP, junior researcher specialized in imaging) screened the identified citations to determine whether they met predefined inand exclusion criteria. If disagreements could not be resolved by consensus, a third reviewer (CB, clinical epidemiologist with over 15 years of experience in conducting systematic reviews) was consulted. Only original studies that provided data to construct contingency tables were included. Exclusion criteria were spinal fusion for the indications bone fracture, tumor, infection; time interval between surgery and index test less than 6 months; patient population smaller than ten; cervical fusion; animal studies; in vitro studies.

\section{Data extraction}

Standard reference data, population characteristics, details on spinal fusion, index test, reference test, and time intervals were extracted by the reviewers (PW, MP). Disagreements were resolved by consensus. Besides study characteristics, diagnostic accuracy data was extracted. Since the outcome was dichotomous (diagnosis was either pseudarthrosis or fusion), contingency tables were constructed. We also recorded whether the results originated from per-patient-, per-level-, or per-side-based analysis.

\section{Methodological quality}

The methodological quality of each selected study was assessed independently by the reviewers according to the Quality Assessment for Diagnostic Accuracy Studies 2 (QUADAS-2) tool [19]. The QUADAS-2 tool consists of four key domains that discuss patient selection, index test, reference standard, flow of patients through the study, and timing of the index test and reference standard. Each domain was scored in terms of risk of bias and concerns regarding applicability to the research question. Disagreements were resolved by consensus.

\section{Data synthesis and statistical analysis}

Pseudarthrosis was defined as a positive test result and fusion as a negative test result. Diagnostic accuracy values were calculated from the extracted contingency tables. Continuity correction was applied to studies with zero-cell counts by adding 0.5 to all cells of the study [20]. Per index test, the studies describing that test were considered for inclusion into subgroup meta-analysis.

\section{Inclusion in meta-analysis}

Meta-analysis was only performed when studies evaluating the same modality were not significantly hampered by clinical heterogeneity. Studies were considered clinically heterogeneous when patient groups, outcome measures, and/or the execution of index tests were considerably different.

The random effect model was employed during metaanalyses to account for unobserved sources of variation [21]. The odds ratio (OR) was used as the principal summary measure in meta-analysis. The higher the OR, the better the discriminatory performance. An OR of 1 indicates a test that does not discriminate between patients with pseudarthrosis and patients with fusion [22]. An OR below 1 suggests a negative association between index test and surgical exploration. Analyses were performed using the Stata statistical software package, version 14.1 (StataCorp, College Station, TX, USA). 


\section{Results}

\section{Identification of studies}

One hundred sixty-five potentially relevant references were identified through database search. After screening, 15 studies were included in this review, reporting on eight modalities: plain radiography, flexion extension radiography (FE radiography), computed tomography (CT), single-photon emission computed tomography (SPECT), planar scintigraphy, polytomography, ultra sound/sonography (US) and ${ }^{18} \mathrm{~F}$-fluoride positron emission tomography/computed tomography (PET/CT). The study selection flowchart is detailed in Fig. 1. The level of evidence of the included studies ranged from I to III.

\section{Data extraction}

Study characteristics of the 15 included studies are listed in Table 1. The number of levels fused in a single patient during initial surgery ranged from 1 to 13 levels. Eight articles monitored pseudarthrosis per patient, five monitored each level separately, and two made a distinction between the left and right side of each operated level. All articles reported that persistent low back pain and/or suspicion of pseudarthrosis was the reason for surgical exploration. The time interval between initial surgery and surgical exploration ranged from 6 to 120 months.

\section{Methodological quality assessment}

Table 2 displays the quality assessment according to QUADAS-2. An overview of the distribution of QUADAS2 scores is presented in Fig. 2. Risk of bias on 'flow and timing', 'patient selection', 'index test', and 'reference standard' was classified as high or unclear in $58 \%$ of cases. Common weaknesses related to poor documentation of patient selection and description of the reference standard. Two studies were considered to have low risk of bias in all four domains. Concerns of applicability on 'patient selection', 'index test', and 'reference standard' was classified as high or unclear in $42 \%$ of cases. Three studies were considered to suffer from low applicability concerns over all three domains.

\section{Data synthesis and statistical analysis}

Table 3 shows the diagnostic accuracy values of the included studies, grouped per index test.

\section{Inclusion in meta-analysis}

The studies discussing the index tests SPECT [24, 28] and planar scintigraphy $[14,23,30]$ were considered for inclusion into subgroup meta-analysis further referred to as scintigraphy. McMaster et al. was not included because the time interval between fusion surgery and surgical exploration was deviating too much from the other studies. The remaining four studies were pooled.

Six studies were considered for inclusion in meta-analysis for plain radiography $[14,15,26,27,31,32]$. Fogel et al. was excluded since the low prevalence of pseudarthrosis made the study population incomparable to the other studies (see Table 3). The remaining five studies were considered comparable enough to be pooled. Two articles diagnosed pseudarthrosis per patient $[14,26]$, two per level $[27,31]$, and one per side [15]. We chose to pool these studies despite differences in analysis region since we were mainly interested in the correlation between findings on imaging and surgical exploration. Using the same rationale, no distinction was made between studies on posterolateral and interbody fusion.

Two articles were considered for FE radiography metaanalysis $[14,15]$. Apart from differences in analysis regions, the study characteristics were considered comparable and the studies were therefore pooled.

Six articles were considered for inclusion in CT metaanalysis [14-16, 25, 32, 33]. The study of Brodsky et al. was excluded for lack of sagittal and coronal reconstructions, essential in the assessment of interbody bony fusion $[14,16$, 33, 35]. Laasonen et al. and Larsen et al. were excluded on slice thickness. Thicknesses of 5 and $6 \mathrm{~mm}$ were used respectively, while bony bridging should be assessed using thin slice $\mathrm{CT}$ to be reliable $[16,32,33,35]$. Fogel et al. was excluded for low prevalence of pseudarthrosis compared to the other studies. The posterolateral fusion patient group of Carreon et al. [16] and the interbody fusion patient group Carreon et al. [33] were pooled for CT.

Figure 3 shows a forest plot of the studies selected for subgroup meta-analysis, with their respective weights and resulting pooled ORs. Index tests for which only one study was identified, i.e., US, polytomography, ${ }^{18} \mathrm{~F}$ fluoride PET/CT [15, 29, 34], could inevitably not undergo subgroup meta-analysis. These single studies were, however, evaluated on the same grounds and if considered reliable, included in Table 4 to complement the meta-analysis results. This was only the case for the study on polytomography [15]. For the study on US [29], the authors considered that with the evaluation of ten patients only, US was not investigated thoroughly enough for pseudarthrosis detection. In the ${ }^{18} \mathrm{~F}$-fluoride PET/CT study [34], the reference standard was either surgical exploration or clinical follow-up, based on the index test outcome. This introduced a bias in the patient population that underwent surgical exploration; only patients with a suspicion of pseudarthrosis on ${ }^{18} \mathrm{~F}$-fluoride PET/CT were surgically explored and used to calculate diagnostic accuracy. 


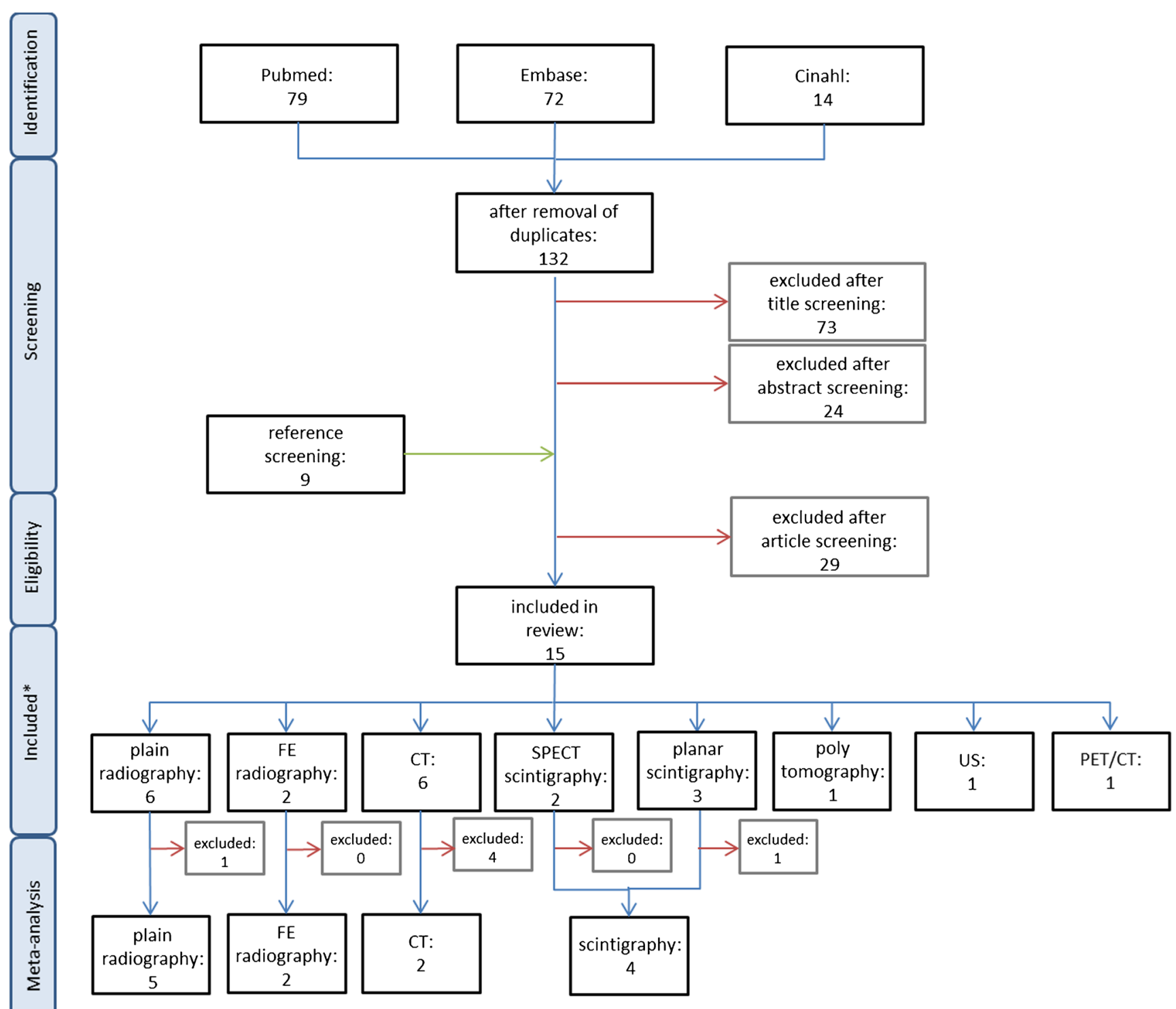

Fig. 1 Flowchart showing the selection of studies from electronic search (identification) until inclusion in the subgroup meta-analyses. Initially, 165 potentially relevant references were identified through database search. One hundred thirty-two were obtained for further screening after removal of 33 duplicates. After removal based on title and abstract screening, the full text of 35 articles was screened and their reference sections

\section{Discussion}

This systematic review summarizes studies in literature that investigated the diagnostic accuracy of imaging modalities to detect pseudarthrosis after thoracolumbar spinal fusion with surgical exploration as the reference standard. Diagnostic accuracy values of individual studies were determined, and for studies of the same modality that were clinically comparable, a pooled $\mathrm{OR}$ was calculated.

Patients after spinal fusion can be monitored by several modalities. Plain radiographs attempt to reveal deficient morphology of the fusion mass as a sign of pseudarthrosis. were scanned for additional eligible studies. Hereafter, 15 studies were included this review, reporting on eight modalities. The meta-analysis part at the bottom of the figure will be discussed in 'inclusion in metaanalysis', which can be found hereafter in the result section. * 3 of the 15 studies described 2 to 4 modalities, leading to 22 included items

However, plain radiographs are projections only $[35,36]$ whereas pseudarthrosis is a three-dimensional problem. The pooled OR of radiography was 7.07. In FE radiography, radiographs are made during flexion and extension of the spinal column to detect motion in the operated segment as a sign of pseudarthrosis. Cases exist where no signs of pseudarthrosis were found on plain radiography, CT, and MRI, but FE radiography detected the pseudarthrosis by unveiling motion between the segments [37]. However, on the other hand, absence of motion does not necessarily correspond with solid fusion and the presence of motion is not directly related to pseudarthrosis [12, 38-40]. Furthermore, no consensus exists 


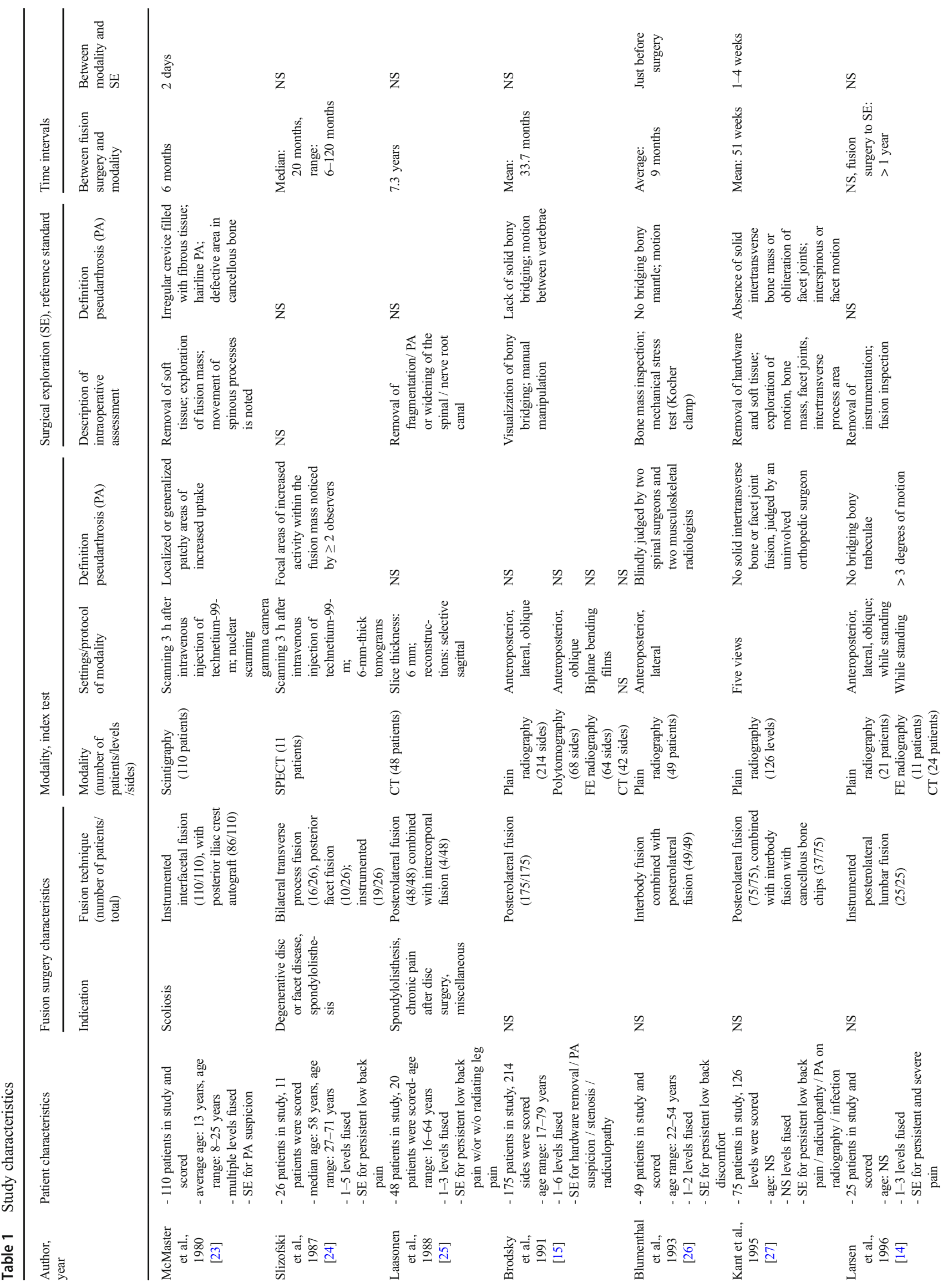



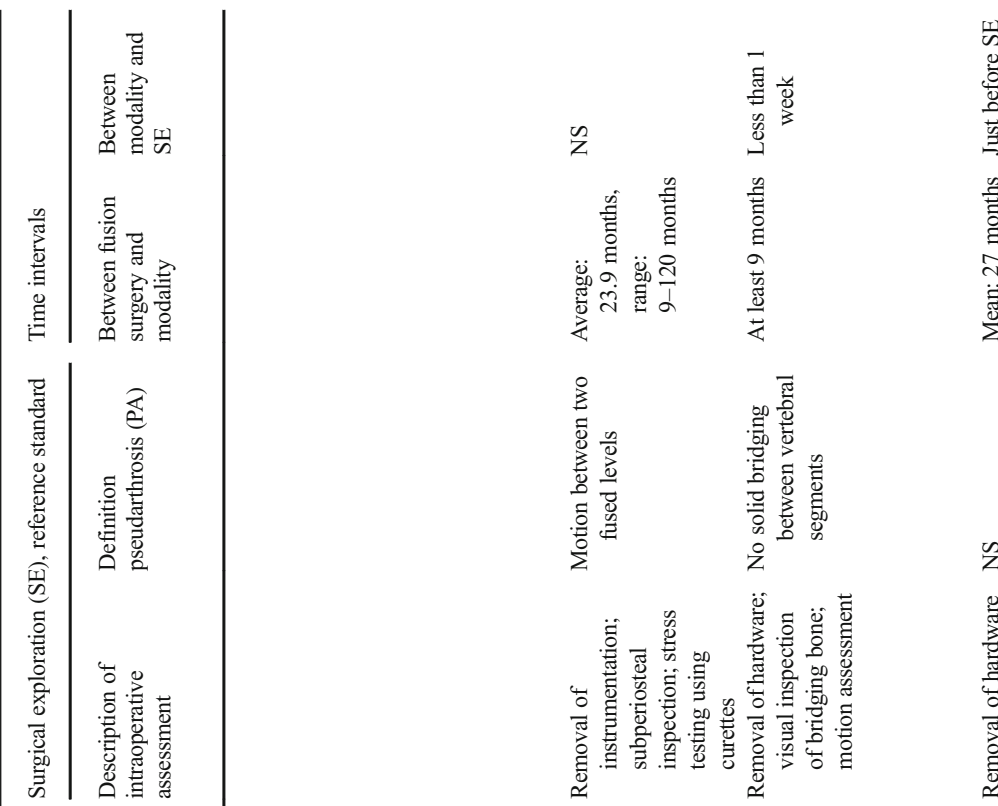

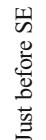

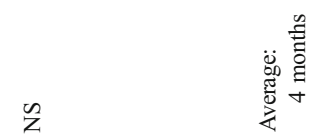

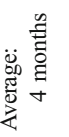
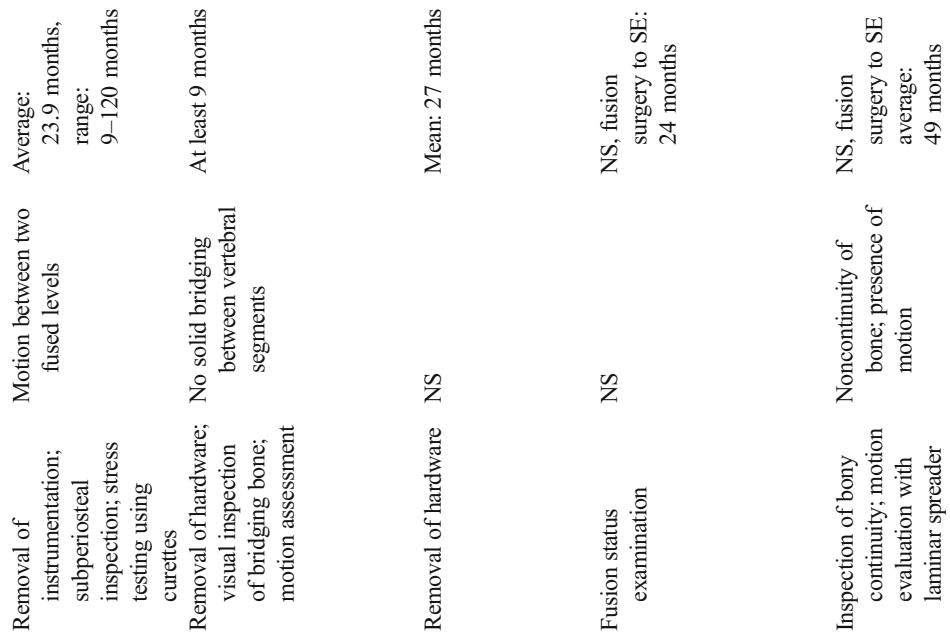

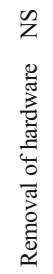

资
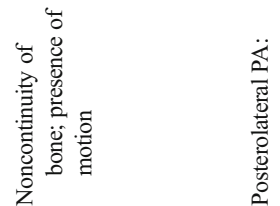

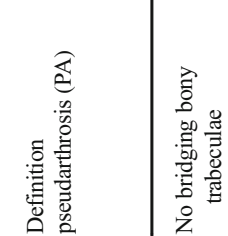

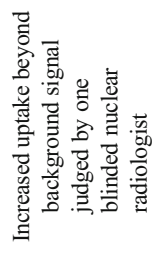

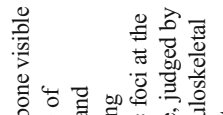

落

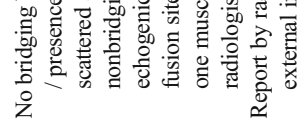

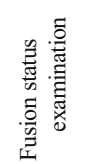

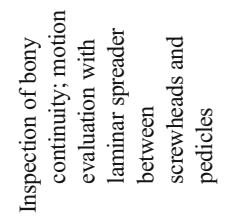

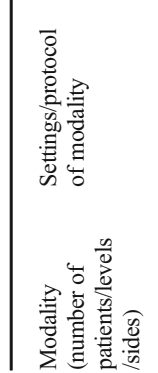

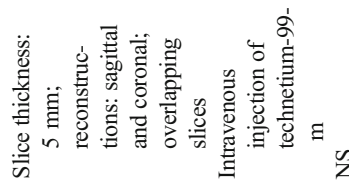

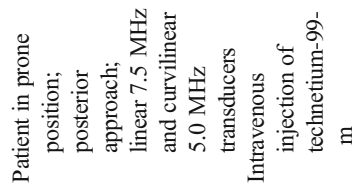

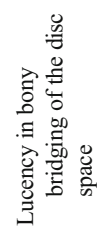

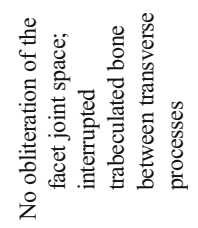

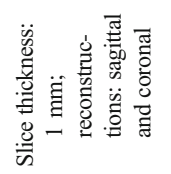

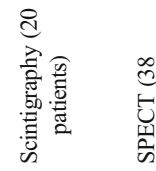

焉

氶

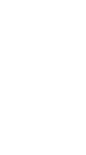

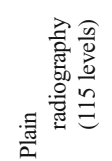

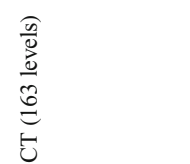

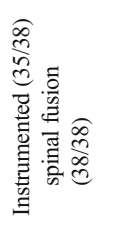

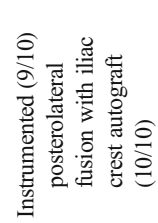

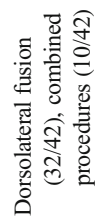

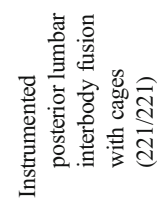

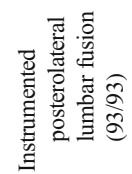

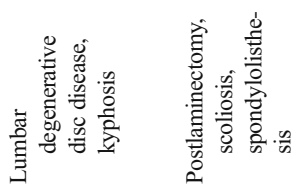

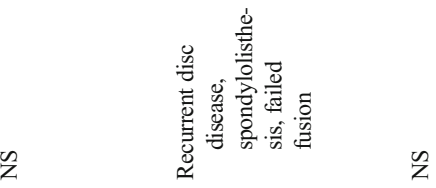

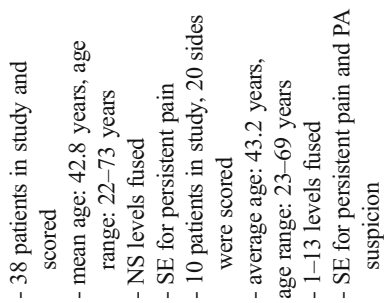

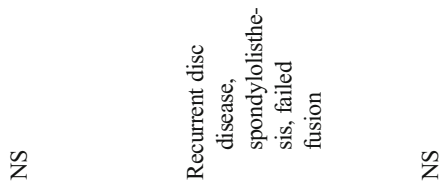

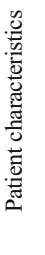

吉

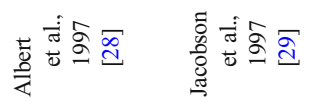

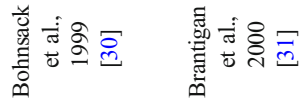

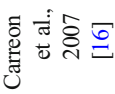




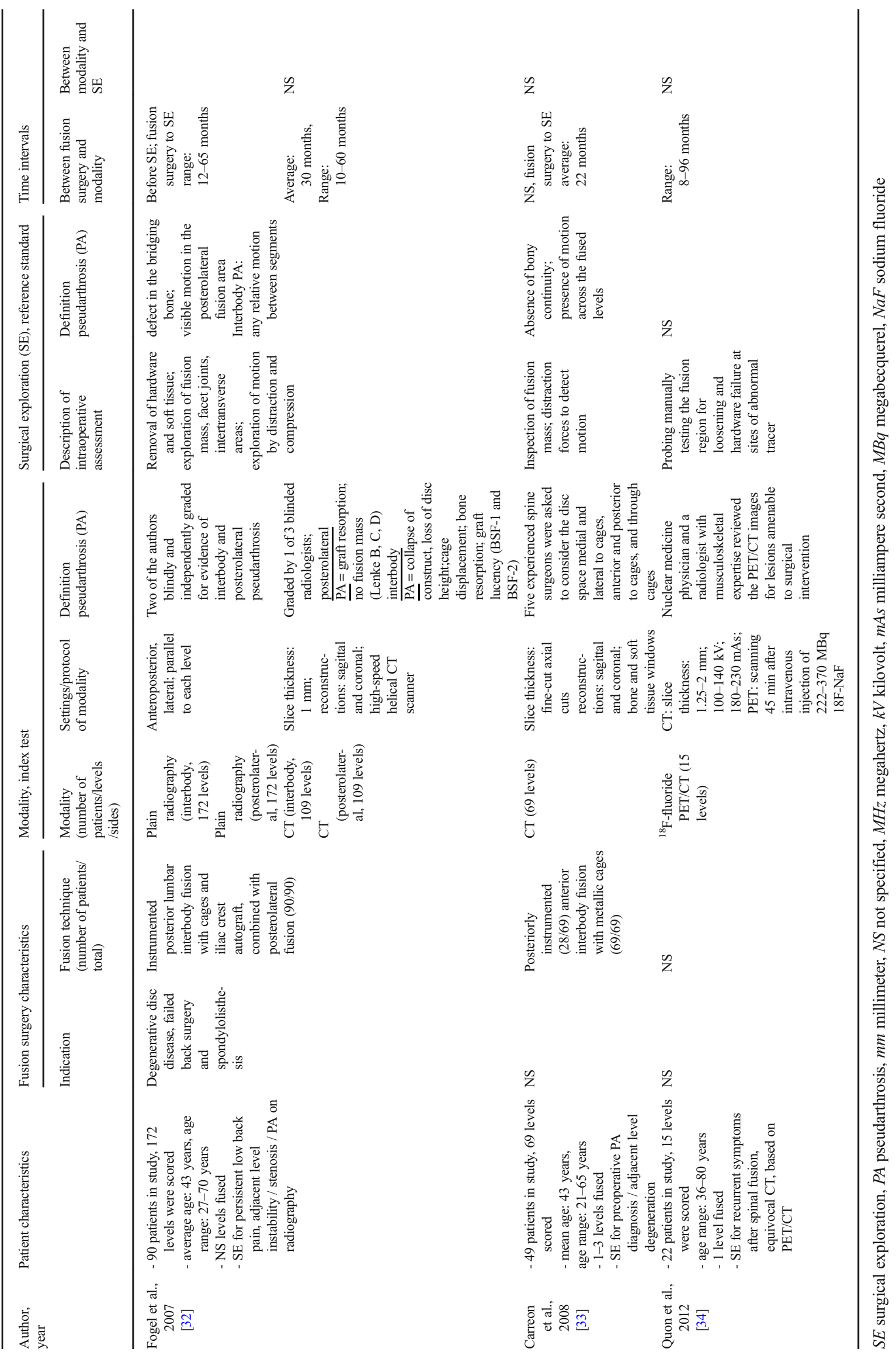


Table 2 QUADAS-2 results for the 15 studies included in this review

\begin{tabular}{|c|c|c|c|c|c|c|c|}
\hline \multirow[t]{2}{*}{ Study } & \multicolumn{4}{|c|}{ RISK OF BIAS } & \multicolumn{3}{|c|}{ APPLICABILITY CONCERNS } \\
\hline & $\begin{array}{c}\text { PATIENT } \\
\text { SELECTION }\end{array}$ & INDEX TEST & $\begin{array}{l}\text { REFERENCE } \\
\text { STANDARD }\end{array}$ & $\begin{array}{l}\text { FLOW AND } \\
\text { TIMING }\end{array}$ & $\begin{array}{c}\text { PATIENT } \\
\text { SELECTION }\end{array}$ & $\begin{array}{c}\text { INDEX } \\
\text { TEST }\end{array}$ & $\begin{array}{l}\text { REFERENCE } \\
\text { STANDARD }\end{array}$ \\
\hline McMaster et al. 1980 [23] & ? & $\because$ & 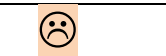 & (:) & (:) & ? & ? \\
\hline Slizofski et al. 1987 [24] & 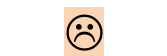 & (:) & ? & 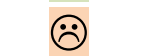 & ? & ; & ? \\
\hline Laasonen et al. 1988 [25] & $\because$ & : & ? & : & ? & (;) & ? \\
\hline Brodsky et al. 1991 [15] & ? & 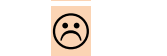 & ? & ? & $\ddot{\theta}$ & ? & (:) \\
\hline Blumenthal et al. 1993 [26] & ? & ? & (:) & (:) & 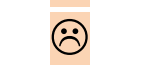 & ;) & ;) \\
\hline Kant et al. 1995 [27] & ? & (:) & 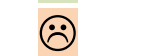 & ? & ;) & (;) & ; \\
\hline Larsen et al. 1996 [14] & (:) & (:) & ? & (:) & (:) & (:) & ? \\
\hline Albert et al. 1997 [28] & (;) & (:) & (;) & (:) & (:) & 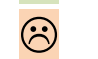 & ;) \\
\hline Jacobson et al. 1997 [29] & (:) & ? & (:) & (:) & (:) & (:) & (:) \\
\hline Bohnsack et al. 1999 [30] & (;) & $:$ & ? & (:) & (:) & ? & ? \\
\hline Brantigan et al. 2000 [31] & ? & ;) & ? & 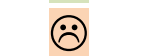 & 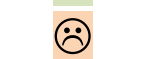 & (;) & ? \\
\hline Carreon et al. 2007 [16] & ? & (;) & ? & ? & 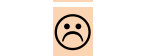 & (:) & (:) \\
\hline Fogel et al. 2008 [32] & 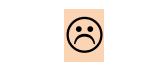 & (;) & (;) & ? & (:) & (;) & (:) \\
\hline Carreon et al. 2008 [33] & (:) & (:) & (:) & (:) & $\ddot{\theta}$ & (:) & (:) \\
\hline Quon et al. 2012 [34] & (2) & ? & $\ddot{\theta}$ & $\ddot{\theta}$ & (:) & ? & (;) \\
\hline
\end{tabular}

on the threshold of allowable motion in a fused segment [40-42]. With a pooled OR of 4.00, FE radiography does not seem to outperform plain radiography. In polytomography, several radiographs along different sectional planes are taken. Going from a single slice in radiography to several planes in polytomography, the OR increased to 10.15 . However, polytomography seems to be outdated by CT developments and currently not frequently used. CT offers three-dimensional osseous detail $[33,35]$. After meta-analysis, CT was the modality with the highest OR in this review. Besides detection of bridging trabecular bone, $\mathrm{CT}$ is able to detect subsidence and lucency around fusion material as possible signs of pseudarthrosis [35]. On the downside, assessment can be complicated by artefacts when metallic cages

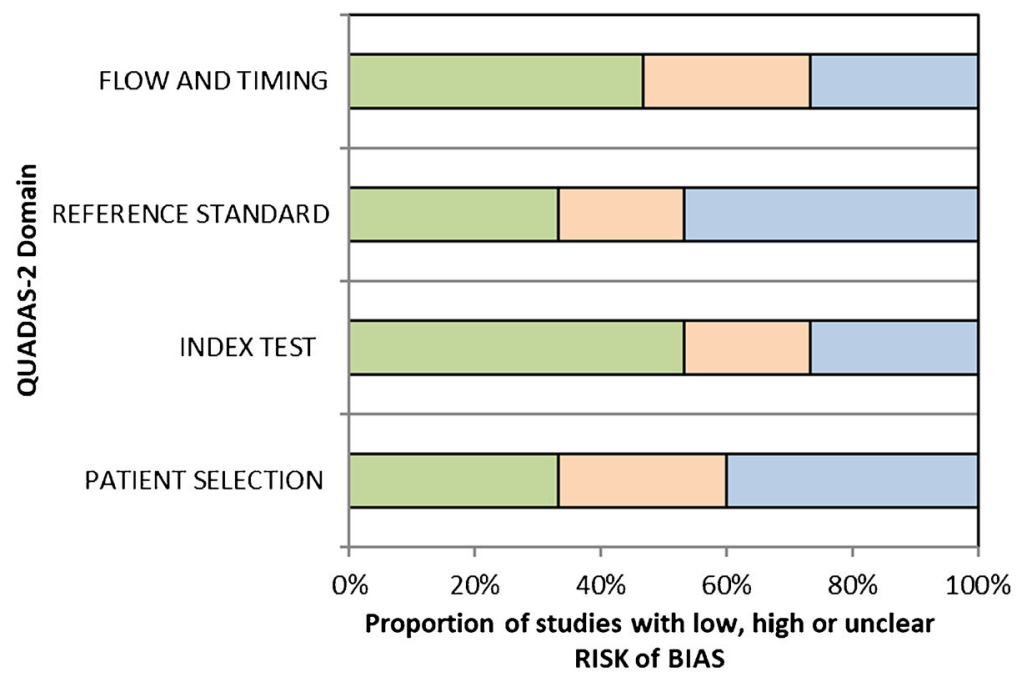

$\square$ Low $\square$ High $\square$ Unclear

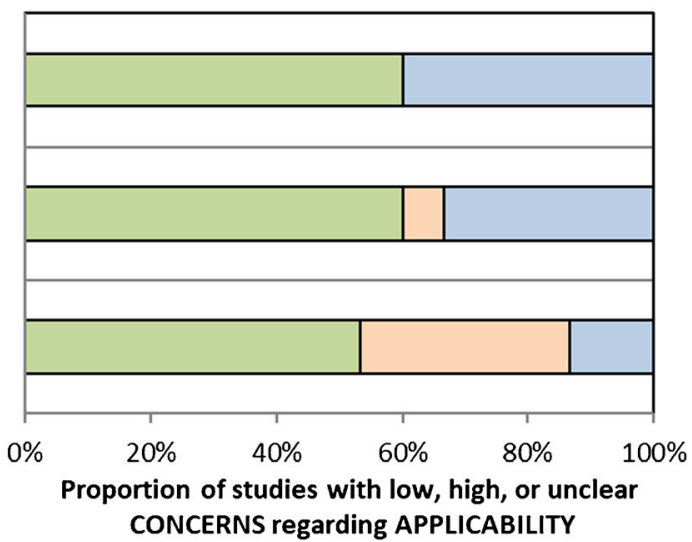

Fig. 2 Stacked bar charts of QUADAS-2 scores presenting a quick overview of the methodological quality of the 15 included studies, expressed as a percentage of studies that met each criterion. For each quality

domain, the proportion of included studies that suggest low, high, or unclear risk of bias and/or concerns regarding applicability are displayed in green, orange, and blue, respectively 
Table 3 Sensitivity, specificity, positive predictive value (PPV), negative predictive value (NPV), positive and negative likelihood ratios (LR+, LR-), prevalence of pseudarthrosis, accuracy ((true positive + true negative) / (total)) and OR values with corresponding 95\% confidence intervals for the seven index tests

\begin{tabular}{|c|c|c|c|c|c|c|c|c|c|c|}
\hline Author & Sensitivity & Specificity & PPV & NPV & $\mathrm{LR}+$ & LR- & Prevalence & Accuracy & OR & $(95 \% \mathrm{CI})$ \\
\hline \multicolumn{11}{|l|}{ Scintigraphy } \\
\hline McMaster et al. 1980 [23] & 0.86 & 0.94 & 0.50 & 0.99 & 14.71 & 0.15 & 0.06 & 0.94 & 97.00 & $(10.00-940.69)$ \\
\hline Slizofski et al. 1987 [24] & 0.75 & 0.83 & 0.94 & 0.50 & 4.50 & 0.30 & 0.77 & 0.77 & 15.00 & $(0.52-430.47)$ \\
\hline Larsen et al. 1996 [14] & 0.25 & 0.83 & 0.50 & 0.63 & 1.50 & 0.90 & 0.40 & 0.60 & 1.67 & $(0.18-15.13)$ \\
\hline Albert et al. 1997 [28] & 0.50 & 0.58 & 0.41 & 0.67 & 1.20 & 0.86 & 0.37 & 0.55 & 1.40 & $(0.37-5.27)$ \\
\hline Bohnsack et al. 1999 [30] & 0.50 & 0.92 & 0.40 & 0.95 & 6.33 & 0.54 & 0.10 & 0.88 & 11.67 & $(1.18-114.90)$ \\
\hline \multicolumn{11}{|l|}{ Plain radiography } \\
\hline Brodsky et al. 1991 [15] & 0.60 & 0.89 & 0.78 & 0.76 & 5.30 & 0.45 & 0.41 & 0.77 & 11.77 & $(8.13-17.04)$ \\
\hline Blumenthal et al. 1993 [26] & 0.55 & 0.71 & 0.18 & 0.93 & 1.90 & 0.63 & 0.10 & 0.69 & 3.01 & $(1.55-5.84)$ \\
\hline Kant et al. 1995 [27] & 0.38 & 0.85 & 0.54 & 0.76 & 2.57 & 0.72 & 0.31 & 0.71 & 3.56 & $(1.48-8.52)$ \\
\hline Larsen et al. 1996 [14] & 0.89 & 0.42 & 0.53 & 0.83 & 1.52 & 0.27 & 0.43 & 0.62 & 5.71 & $(0.53-61.41)$ \\
\hline Brantigan et al. 2000 [31] & 0.55 & 0.97 & 0.67 & 0.95 & 18.91 & 0.47 & 0.10 & 0.93 & 40.40 & $(7.75-210.65)$ \\
\hline Fogel et al. 2007 [32] & 0.90 & 0.77 & 0.10 & 1.00 & 3.85 & 0.13 & 0.03 & 0.77 & 29.51 & $(1.55-560.03)$ \\
\hline \multicolumn{11}{|l|}{ FE radiography } \\
\hline Brodsky et al. 1991 [15] & 0.37 & 0.96 & 0.86 & 0.71 & 9.74 & 0.66 & 0.39 & 0.73 & 14.86 & $(5.48-40.28)$ \\
\hline Larsen et al. 1996 [14] & 0.10 & 0.81 & 0.25 & 0.59 & 0.53 & 1.11 & 0.38 & 0.54 & 0.48 & $(0.02-14.70)$ \\
\hline \multicolumn{11}{|l|}{ CT } \\
\hline Laasonen et al. 1988 [25] & 0.80 & 0.80 & 0.80 & 0.80 & 4.00 & 0.25 & 0.50 & 0.80 & 16.00 & $(1.78-143.15)$ \\
\hline Brodsky et al. 1991 [15] & 0.39 & 0.28 & 0.13 & 0.63 & 0.55 & 2.14 & 0.22 & 0.31 & 0.26 & $(0.12-0.57)$ \\
\hline Larsen et al. 1996 [14] & 0.78 & 0.53 & 0.50 & 0.80 & 1.67 & 0.42 & 0.38 & 0.63 & 4.00 & $(0.62-25.96)$ \\
\hline Carreon et al. 2007 [16] & 0.91 & 0.69 & 0.41 & 0.97 & 2.90 & 0.14 & 0.20 & 0.73 & 21.22 & $(6.11-73.67)$ \\
\hline Fogel et al. 2007 [32] & 0.90 & 0.70 & 0.13 & 0.99 & 3.03 & 0.14 & 0.05 & 0.71 & 21.29 & $(1.11-407.21)$ \\
\hline Carreon et al. 2008 [33] & 0.93 & 0.46 & 0.57 & 0.90 & 1.73 & 0.14 & 0.43 & 0.67 & 12.00 & $(2.51-57.48)$ \\
\hline \multicolumn{11}{|l|}{ Polytomography } \\
\hline Brodsky et al. 1991 [15] & 0.84 & 0.65 & 0.73 & 0.79 & 2.44 & 0.24 & 0.53 & 0.75 & 10.15 & $(5.49-18.78)$ \\
\hline \multicolumn{11}{|l|}{ US } \\
\hline Jacobson et al. 1997 [29] & 0.95 & 0.59 & 0.70 & 0.93 & 2.33 & 0.08 & 0.50 & 0.77 & 30.33 & $(1.39-660.76)$ \\
\hline \multicolumn{11}{|l|}{$\mathrm{PET} / \mathrm{CT}$} \\
\hline Quon et al. 2012 [34] & 0.97 & 0.25 & 0.91 & 0.50 & 1.29 & 0.13 & 0.88 & 0.88 & 9.67 & $(0.14-688.10)$ \\
\hline
\end{tabular}

and/or instrumentation are used $[14,32,33,35]$. Technological improvements such as iterative reconstruction and dual-energy scanning are likely to improve accuracy [43]. Whether CT alone is sufficient for clinical decision-making is under debate. Choudhri et al. stated that multiple modalities should be considered for the noninvasive evaluation of symptomatic patients with suspected failure of spinal fusion [38]. US can demonstrate callus formation and bone healing [44, 45]. Although the first study assessing the role of US for pseudarthrosis detection in ten patients seemed promising in 1997 [29], it has been the only study since.

Pseudarthrosis diagnosis can also be based on abnormalities in bone metabolism. Studies on SPECT and planar scintigraphy were grouped together in meta-analysis since both modalities use ${ }^{99 \mathrm{~m}} \mathrm{Tc}$-labeled phosphonates as tracer. ${ }^{99 \mathrm{~m}} \mathrm{Tc}$ labeled phosphonates are adsorbed onto or into the crystalline structure of hydroxyapatite to mark bone remodeling. With a pooled OR of 2.91, scintigraphy amounted to the lowest OR value after subgroup meta-analyses. An analog to ${ }^{99 \mathrm{~m}} \mathrm{Tc}-\mathrm{la}-$ beled phosphonates is ${ }^{18} \mathrm{~F}$-fluoride. Both tracers have similar uptake mechanisms [46] but ${ }^{18} \mathrm{~F}$-fluoride decays via positron emission and can therefore be imaged by PET. Compared to ${ }^{99 \mathrm{~m}}$ Tc SPECT, ${ }^{18} \mathrm{~F}$-fluoride PET provides higher resolution, higher sensitivity, and better quantification capabilities [47]. PET combined with CT allows localization of abnormal uptake, which might enhance discriminative power [6]. Quon et al. evaluated PET/CT as index test for pseudarthrosis diagnosis [34]. The results seem promising but studies of higher methodological quality should be conducted to draw firmer conclusions on its value in pseudarthrosis diagnosis.

In the database search, one paper evaluating MRI [48] and one paper evaluating RSA as index test [49] were identified but not included. In MRI, bridging bone between endplates can be visualized [50] and changes in 
Study

OR $(95 \% \mathrm{Cl})$

$\%$

SCINTIGRAPHY

Slizofski et al. 1987

Larsen et al. 1996

Albert et al. 1997

Bohnsack et al. 1999

Subtotal

PLAIN X-ray

Brodsky et al. 1991

Blumenthal et al. 1993

Kant et al. 1995

Larsen et al. 1996

Brantigan et al. 2000

Subtotal

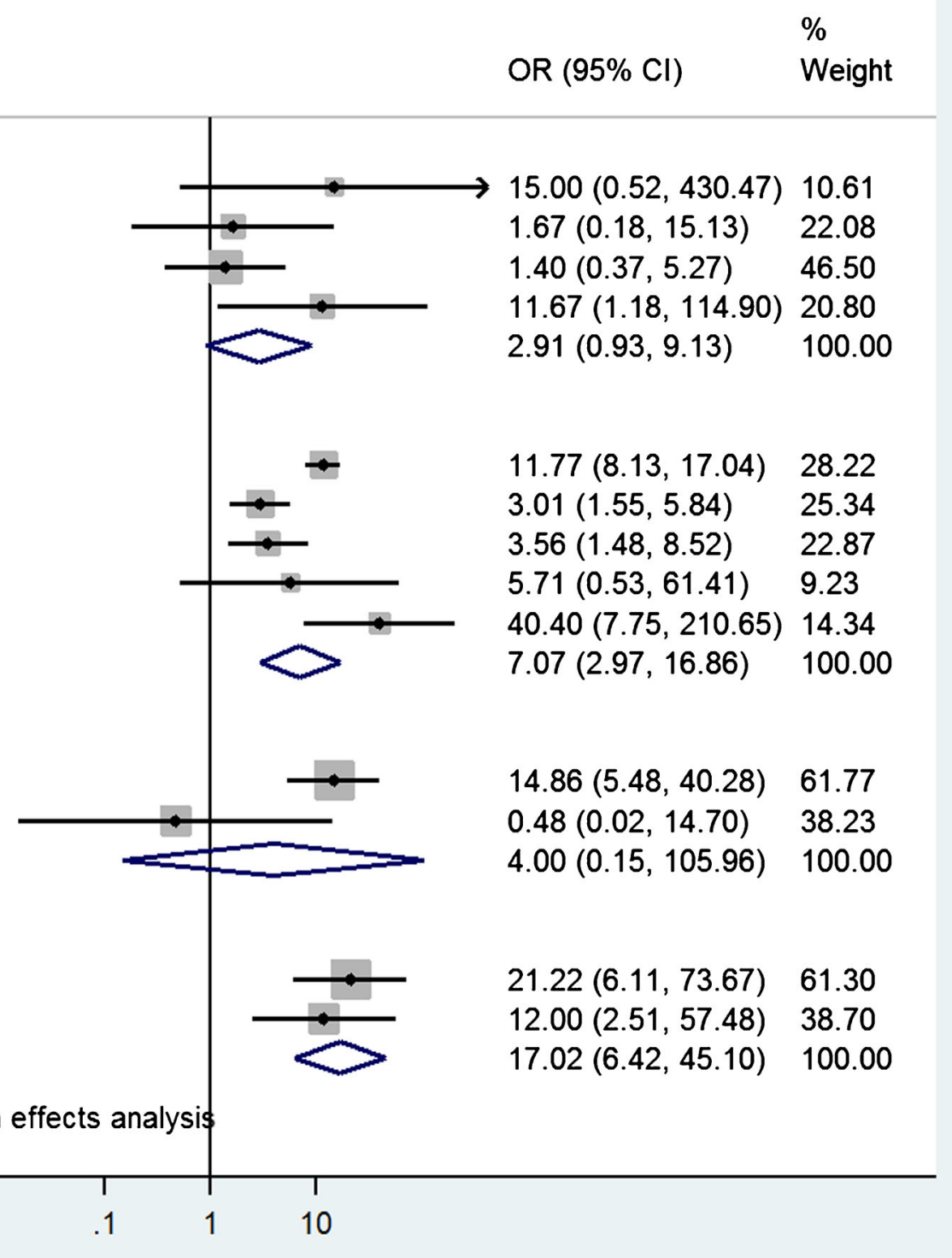

FE X-ray

Brodsky et al. 1991

Larsen et al. 1996

Subtotal

CT

Carreon et al. 2007

Carreon et al. 2008

Subtotal

Fig. 3 Forest plot of the included studies in the meta-analysis per modality. The size of each square is proportional to the study's weight

the vertebral body marrow signal as a sign of functional instability can be detected $[48,51]$. On the downside, metal instrumentation complicates pseudarthrosis assessment in MRI. Length of follow-up was too short for the study of Lang et al. to be included. RSA is able to accurately quantify micromovements of vertebrae relative to each other, to evaluate lumbosacral stability [38, 42]. The study of Pape et al. could not be used to calculate the diagnostic accuracy of RSA for pseudarthrosis detection since all patients attained fusion.

Table 4 Overview of ORs as determined from included studies

\begin{tabular}{llll}
\hline & Number of studies & Number of patients & (Pooled) OR [95\% CI] \\
\hline Scintigraphy [14, 24, 28, 30] & 4 & 93 & $2.91[0.93-9.13]$ \\
Plain radiography [14, 15, 26, 27, 31] & 5 & 398 & $7.07[2.97-16.86]$ \\
FE radiography [14, 15] & 2 & 75 & $4.00[0.15-105.96]$ \\
CT [16, 33] & 2 & 142 & $17.02[6.42-45.10]$ \\
Polytomography [15] & 1 & 68 & $10.15[5.49-18.78]$ \\
\hline
\end{tabular}


A strength of the present review was that the patient populations of the included studies resemble patient populations that would undergo these tests in clinical practice to either confirm or exclude pseudarthrosis, since all suffered from persisting or recurrent pain after spinal fusion. The methodological choice to only include studies that compared an index modality to the gold standard of surgical exploration was a strength on one hand since it is the most valid way to assess the diagnostic accuracy of a modality [14]. However, it was a weakness on the other hand, since it meant the exclusion of newer studies that evaluate state-of-the-art modalities. The study design of using surgical exploration as gold standard is no longer ethical or practical in clinical practice. As a result, the value of state-of-the-art modalities could not be discussed in this review and are still left to be evaluated. Another weakness of the study was that studies in meta-analysis, although relatively comparable, did show differences in spinal fusion technique, types of cages and instrumentation, imaging characteristics, pseudarthrosis definition, experience of the observers, and patient characteristics. Especially the time interval between spinal fusion and index test was highly variable between studies. Furthermore, the interpretation of index test results was incomplete in some studies. Imaging findings were reported but not always classified as either pseudarthrosis or fused. In these cases, the cut-off point was determined by the writers of this review, which is arbitrary, although not necessarily far from clinical practice. Studies also reported poorly on patient population inclusion criteria. Lack of information may have led to incorrect inclusion of studies in meta-analyses and weakens the findings of this review.

To conclude, with a pooled OR of 17.02, CT can be considered the most accurate non-invasive imaging modality for the detection of pseudarthrosis after spinal fusion from this review.

\section{Compliance with ethical standards}

Conflict of interest The authors declare that they have no conflict of interest.

Open Access This article is distributed under the terms of the Creative Commons Attribution 4.0 International License (http:// creativecommons.org/licenses/by/4.0/), which permits unrestricted use, distribution, and reproduction in any medium, provided you give appropriate credit to the original author(s) and the source, provide a link to the Creative Commons license, and indicate if changes were made.

Publisher's note Springer Nature remains neutral with regard to jurisdictional claims in published maps and institutional affiliations.

\section{References}

1. Volinn E. The epidemiology of low back pain in the rest of the world. Spine. 1997;22(15):1798.
2. Vos. Global, regional, and national incidence, prevalence, and years lived with disability for 301 acute and chronic diseases and injuries in 188 countries, 1990-2013: a systematic analysis for the global burden of disease study 2013. Lancet (London, England). 2015;386(9995):743-800.

3. Grubb SA, Lipscomb HJ. Results of lumbosacral fusion for degenerative disc disease with and without instrumentation. Two- to fiveyear follow-up. Spine. 1992;17(3):349-55.

4. O'Beirne J, O'Neill D, Gallagher J, Williams DH. Spinal fusion for back pain: a clinical and radiological review. J Spinal Disord. 1992;5(1):32-8.

5. Larsen JM, Capen DA. Pseudarthrosis of the lumbar spine. J Am Acad Orthop Surg. 1997;5(3):153-62.

6. Rager O, Schaller K, Payer M, Tchernin D, Ratib O, Tessitore E. SPECT/CT in differentiation of pseudarthrosis from other causes of back pain in lumbar spinal fusion: report on 10 consecutive cases. Clin Nucl Med. 2012;37(4):339-43.

7. Raizman NM, O'Brien JR, Poehling-Monaghan KL, Yu WD. Pseudarthrosis of the spine. J Am Acad Orthop Surg. 2009;17(8): 494-503.

8. Heggeness MH, Esses SI. Classification of pseudarthroses of the lumbar spine. Spine. 1991;16(8 Suppl):S449-54.

9. Rothman RH, Booth R. Failures of spinal fusion. Orthop Clin N Am. 1975;6(1):299-304.

10. Brown CW, Orme TJ, Richardson HD. The rate of pseudarthrosis (surgical nonunion) in patients who are smokers and patients who are nonsmokers: a comparison study. Spine. 1986;11(9):942-3.

11. Finnegan WJ, Fenlin JM, Marvel JP, Nardini RJ, Rothman RH. Results of surgical intervention in the symptomatic multiplyoperated back patient. Analysis of sixty-seven cases followed for three to seven years. J Bone Joint Surg (Am Vol). 1979;61(7):107782.

12. Frymoyer JW, Hanley EN Jr, Howe J, Kuhlmann D, Matteri RE. A comparison of radiographic findings in fusion and nonfusion patients ten or more years following lumbar disc surgery. Spine. 1979;4(5):435-40.

13. Waddell G, Kummel EG, Lotto WN, Graham JD, Hall H, McCulloch JA. Failed lumbar disc surgery and repeat surgery following industrial injuries. J Bone Joint Surg Am. 1979;61(2):2017.

14. Larsen JM, Rimoldi RL, Capen DA, Nelson RW, Nagelberg S, Thomas JC Jr. Assessment of pseudarthrosis in pedicle screw fusion: a prospective study comparing plain radiographs, flexion/ extension radiographs, CT scanning, and bone scintigraphy with operative findings. J Spinal Disord. 1996;9(2):117-20.

15. Brodsky AE, Kovalsky ES, Khalil MA. Correlation of radiologic assessment of lumbar spine fusions with surgical exploration. Spine. 1991;16(6 Suppl):S261-5.

16. Carreon LY, Djurasovic M, Glassman SD, Sailer P. Diagnostic accuracy and reliability of fine-cut CT scans with reconstructions to determine the status of an instrumented posterolateral fusion with surgical exploration as reference standard. Spine. 2007;32(8):8925.

17. Hutton B, Salanti G, Caldwell DM, Chaimani A, Schmid CH, Cameron $\mathrm{C}$, et al. The PRISMA extension statement for reporting of systematic reviews incorporating network meta-analyses of health care interventions: checklist and explanations. Ann Intern Med. 2015;162(11):777-84.

18. Liberati A, Altman DG, Tetzlaff J, Mulrow C, Gotzsche PC, Ioannidis JP, et al. The PRISMA statement for reporting systematic reviews and meta-analyses of studies that evaluate health care interventions: explanation and elaboration. J Clin Epidemiol. 2009;62(10):e1-34.

19. Whiting PF, Rutjes AW, Westwood ME, Mallett S, Deeks JJ, Reitsma JB, et al. QUADAS-2: a revised tool for the quality 
assessment of diagnostic accuracy studies. Ann Intern Med. 2011;155(8):529-36.

20. Higgins JP, Green S. Cochrane handbook for systematic reviews of interventions. Hoboken: John Wiley \& Sons; 2011.

21. Ma X, Nie L, Cole SR, Chu H. Statistical methods for multivariate meta-analysis of diagnostic tests: an overview and tutorial. Stat Methods Med Res. 2016;25(4):1596-619.

22. Glas AS, Lijmer JG, Prins MH, Bonsel GJ, Bossuyt PM. The diagnostic odds ratio: a single indicator of test performance. J Clin Epidemiol. 2003;56(11):1129-35.

23. McMaster MJ, Merrick MV. The scintigraphic assessment of the scoliotic spine after fusion. J Bone Joint Surg Br Vol. 1980;62-B(1): 65-72.

24. Slizofski WJ, Collier BD, Flatley TJ, Carrera GF, Hellman RS, Isitman AT. Painful pseudarthrosis following lumbar spinal fusion: detection by combined SPECT and planar bone scintigraphy. Skelet Radiol. 1987;16(2):136-41.

25. Laasonen EM, Soini J. Low-back pain after lumbar fusion. Surgical and computed tomographic analysis. Spine. 1989;14(2):210-3.

26. Blumenthal SL, Gill K. Can lumbar spine radiographs accurately determine fusion in postoperative patients? Correlation of routine radiographs with a second surgical look at lumbar fusions. Spine. 1993;18(9):1186-9.

27. Kant AP, Daum WJ, Dean SM, Uchida T. Evaluation of lumbar spine fusion. Plain radiographs versus direct surgical exploration and observation. Spine. 1995;20(21):2313-7.

28. Albert TJ, Pinto M, Smith MD, Balderston RA, Cotler JM, Park $\mathrm{CH}$. Accuracy of SPECT scanning in diagnosing pseudoarthrosis: a prospective study. J Spinal Disord. 1998;11(3):197-9.

29. Jacobson JA, Starok M, Pathria MN, Garfin SR. Pseudarthrosis: US evaluation after posterolateral spinal fusion: work in progress. Radiology. 1997;204(3):853-8.

30. Bohnsack M, Gosse F, Ruhmann O, Wenger K. The value of scintigraphy in the diagnosis of pseudarthrosis after spinal fusion surgery. J Spinal Disord. 1999;12(6):482-4.

31. Brantigan JW, Steffee AD, Lewis ML, Quinn LM, Persenaire JM. Lumbar interbody fusion using the Brantigan $\mathrm{I} / \mathrm{F}$ cage for posterior lumbar interbody fusion and the variable pedicle screw placement system: two-year results from a Food and Drug Administration investigational device exemption clinical trial. Spine. 2000;25(11):1437-46.

32. Fogel GR, Toohey JS, Neidre A, Brantigan JW. Fusion assessment of posterior lumbar interbody fusion using radiolucent cages: $\mathrm{X}$-ray films and helical computed tomography scans compared with surgical exploration of fusion. Spine J. 2008;8(4):570-7.

33. Carreon LY, Glassman SD, Schwender JD, Subach BR, Gornet MF, Ohno S. Reliability and accuracy of fine-cut computed tomography scans to determine the status of anterior interbody fusions with metallic cages. Spine J. 2008;8(6):998-1002.

34. Quon A, Dodd R, Iagaru A, de Abreu MR, Hennemann S, Alves Neto JM, et al. Initial investigation of (1)(8)F-NaF PET/CT for identification of vertebral sites amenable to surgical revision after spinal fusion surgery. Eur J Nucl Med Mol Imaging. 2012;39(11): $1737-44$.
35. Williams AL, Gornet MF. Burkus JK. CT evaluation of lumbar interbody fusion: current concepts. AJNR Am J Neuroradiol. 2005;26(8):2057-66.

36. Schuler TC, Subach BR, Branch CL, Foley KT, Burkus JK. Segmental lumbar lordosis: manual versus computer-assisted measurement using seven different techniques. J Spinal Disord Tech. 2004;17(5):372-9.

37. Shen FH, Samartzis D. Assessment of lumbar fusion: importance of dynamic plain standing X-rays. J Am Coll Surg. 2008;207(6):9556.

38. Choudhri TF, Mummaneni PV, Dhall SS, Eck JC, Groff MW, Ghogawala Z, et al. Guideline update for the performance of fusion procedures for degenerative disease of the lumbar spine. Part 4: radiographic assessment of fusion status. J Neurosurg Spine. 2014;21(1):23-30.

39. McAfee PC, Boden SD, Brantigan JW, Fraser RD, Kuslich SD, Oxland TR, et al. Symposium: a critical discrepancy - a criteria of successful arthrodesis following interbody spinal fusions. Spine. 2001;26(3):320-34

40. Santos ER, Goss DG, Morcom RK, Fraser RD. Radiologic assessment of interbody fusion using carbon fiber cages. Spine. 2003;28(10):997-1001.

41. Hipp JA, Reitman CA, Wharton N. Defining pseudoarthrosis in the cervical spine with differing motion thresholds. Spine. 2005;30(2): $209-10$.

42. Selby MD, Clark SR, Hall DJ, Freeman BJ. Radiologic assessment of spinal fusion. J Am Acad Orthop Surg. 2012;20(11):694-703.

43. Stradiotti P, Curti A, Castellazzi G, Zerbi A. Metal-related artifacts in instrumented spine. Techniques for reducing artifacts in $\mathrm{CT}$ and MRI: state of the art. Eur Spine J. 2009;18(Suppl 1):102-8.

44. Eyres KS, Bell MJ, Kanis JA. Methods of assessing new bone formation during limb lengthening. Ultrasonography, dual-energy X-ray absorptiometry and radiography compared. J Bone Joint Surg Br Vol. 1993;75(3):358-64.

45. Maffulli N, Thornton A. Ultrasonographic appearance of external callus in long-bone fractures. Injury. 1995;26(1):5-12.

46. Wong KK, Piert M. Dynamic bone imaging with $99 \mathrm{mTc}$-labeled diphosphonates and 18F-NaF: mechanisms and applications. J Nucl Med. 2013;54(4):590-9.

47. Rahmim A, Zaidi H. PET versus SPECT: strengths, limitations and challenges. Nucl Med Commun. 2008;29(3):193-207.

48. Lang P, Chafetz N, Genant HK, Morris JM. Lumbar spinal fusion. Assessment of functional stability with magnetic resonance imaging. Spine. 1990;15(6):581-8.

49. Pape D, Adam F, Fritsch E, Muller K, Kohn D. Primary lumbosacral stability after open posterior and endoscopic anterior fusion with interbody implants: a roentgen stereophotogrammetric analysis. Spine. 2000;25(19):2514-8.

50. Kroner AH, Eyb R, Lange A, Lomoschitz K, Mahdi T, Engel A. Magnetic resonance imaging evaluation of posterior lumbar interbody fusion. Spine. 2006;31(12):1365-71.

51. Steinmann JC, Herkowitz HN. Pseudarthrosis of the spine. Clin Orthop Relat Res. 1992;284:80-90. 